Original article

\title{
Quality of services provided by public funded ambulance program: Experience from a northern state in India
}

\author{
Bhaskar Tiwary $^{\mathrm{a}, 1, *}$, Nilima Nilima ${ }^{\mathrm{b}, \mathrm{d}, 1}$, Piyusha Majumdar ${ }^{\mathrm{a}}$, Monika Singh ${ }^{\mathrm{a}, \mathrm{e}, * *}$, \\ Mohd Aihatram Khan ${ }^{c}$ \\ ${ }^{a}$ Indian Institute of Health Management Research, Jaipur, India \\ ${ }^{\mathrm{b}}$ All India Institute of Medical Sciences, Delhi, India \\ ${ }^{\mathrm{c}}$ The Mission Hospital, Durgapur, India \\ ${ }^{\mathrm{d}}$ Indian Institute of Public Health, Delhi, PFHI, India \\ ${ }^{\mathrm{e}}$ CARE India, Bihar, India
}

A R T I C L E I N F O

Keywords:

Ambulances

Quality of patient care

Emergency medical technicians

\begin{abstract}
A B S T R A C T
Background: Ambulance Services are vital in providing pre-hospital treatment and care to help regain life. Timely and safe transport of patients from the emergency scene to the appropriate healthcare facility for further care is a complex process. Administering emergency services in minimal time is a challenge in a country with basic lacunae in infrastructure", making the role of EMTs (emergency medical technicians) and ambulance quality vital in saving lives.

Methods: A descriptive cross-sectional study using a structured questionnaire for the emergency medical technicians and ten parameters to inspect the quality of ambulances was used. Emergency medical technicians in 150 ambulances were interviewed and ambulance was inspected through convenience sampling. Chi-squared test was applied to investigate the association between quality of ambulance \& emergency medical technicians' knowledge. Logistic regression was used to obtain the measure of association adjusted for confounders. SPSS (Statistical Package for Social Sciences) version 25, (Licensed software of IIHMR University, Jaipur) was used for analysis.

Results: Majority of the ambulances $68 \%(\mathrm{n}=102)$ were found to have met the standards. Almost $71 \%$ ( $\mathrm{n}=107$ ) of the EMTs were observed to have below average knowledge. Among ambulances not meeting the standards, 66.7\% ( $\mathrm{n}=101)$ had EMT with below average knowledge. Ambulance quality was found to be independent of the knowledge of EMTs after adjusting for the effects of years of experience and age of the EMTs. Conclusion: Majority of the ambulances were found to have met the standards however public health workers should work towards improving the emergency medical technicians' knowledge on transportation of emergency cases.
\end{abstract}

\section{Introduction}

Among the major attributes, delay in reaching to an appropriate health facility is one of the prime factors contributing to high number of deaths in emergencies. This normally happens either due to lack of readily available and affordable transport facility or inaccessibility for which people fail to access institutional health services. ${ }^{1,2}$ The total life years lost due to trauma accounted for thirty percent of all life years as estimated by the National Trauma Institute in the United States. ${ }^{3}$ Ischemic heart disease and stroke which require prompt emergency services are the leading cause of death due to impediment services of ambulance as estimated by World Health Organization in $2016 .{ }^{4}$

Prompt \& effective transportation of patients from the site of emergency to the hospital's emergency department seems simple but in actual is a complex process. ${ }^{5}$ For the personnel of ambulatory and emergency services administering their services in the minimal time executes their ultimate accomplishment, i.e. reaching the site and transporting the patient to healthcare institution by ambulance in the golden hour where the human beings endangered life can be saved. ${ }^{6}$ Enhancing pre-hospital care for the patients suffering emergency or

\footnotetext{
* Corresponding author. Indian Institute of Health Management Research, Jaipur, India. Mobile: +919482386283.

** Corresponding author. Indian Institute of Health Management Research, Jaipur, India. Mobile: + 918077970523.

E-mail addresses: bhaskar1697@yahoo.com (B. Tiwary), monicasingh2607@gmail.com (M. Singh).

${ }^{1}$ Authors are equally contributing first authors.
} 
trauma can help in reducing morbidity \& mortality.

Poor methods of transportation, lack of infrastructure, lack of public awareness about recognizing emergencies and untrained healthcare professionals are some of the major problems seen in developing countries. ${ }^{8}$ Poor quality \& under maintained medical equipment's, unhygienic conditions of patient compartment in ambulance and delay in reaching the site of emergency are the few factors leading to compromising of patient safety in the ambulances. ${ }^{9}$ MDG-4 \& 5 (Millennium Development Goals) meant for reduction in child and maternal mortality could not achieved till now because of flaw in quality ambulatory care services needed for maternal and child care at appropriate time and place. ${ }^{10,11}$ The transportation of referred pregnant women to appropriate health facilities and end-route stabilizing care plays a pivotal role in preventing maternal deaths in low-income and middle-income countries. ${ }^{12}$ Effective emergency care can avert deaths from acute respiratory and diarrheal conditions and from noncommunicable diseases such as hypertension and other cardiovascular problems. ${ }^{13}$

Deaths due to road traffic accidents in India is expected to cross 2,50000 by the year $2025 .{ }^{14}$ Providing prompt and effective emergency health services by the ambulances is a challenge in country like India, along with planning, regulatory and policy issues. In everchanging landscape of ambulatory care services there is a tradeoff between costs and quality care. ${ }^{15}$ This raises the need for methods and tools that effectively enable decision makers to make optimal use of resources at hand. The quality of care provided during transportation is dependent on the training of healthcare professional in the ambulance which consists of EMTs (emergency medical technicians) and the infrastructure of the ambulance. ${ }^{16}$ Quality of care can be efficient \& effective if the ambulance has state of art facilities necessary for the emergency purpose and skilled emergency medical technicians trained for handling versatile emergency conditions. ${ }^{17}$

Since 2002, the government has implemented many schemes and interventions to improve basic transport and ambulances for pregnant women under the Reproductive and Child Health Program and the National Rural Health Mission. These include the Janani Suraksha Yojana-a cash transfer scheme that covers partial travel costs; regional voucher schemes; state run call center based ambulance systems (108 and 102, also as 104 in many states) and decentralized district level public private partnerships such as Janani Express and local community-based innovations to provide basic transport services. ${ }^{18}$

However, there are gaps identified in these programs as there are no guidelines \& regulations which has to be followed during transportation in emergency cases by the ambulances. ${ }^{19}$ Adequate \& effective quality of care provided during transportation can make an important contribution in reducing avoidable death and disability. It is relevant to carry out the present study as Indian population lacks primary research on quality of ambulances and emergency medical technicians' knowledge during transportation in emergency cases.

\section{Materials \& methods}

\subsection{Study design}

A cross sectional study carried out in Rajasthan, India, from April 1, 2019 to May 31, 2019.

\subsection{Study population \& setting}

The 108-Ambulances operating in Rajasthan, India managed by GVK EMRI (Gunupati Venkata Krishna -Emergency Management Research Institute) was chosen for this study. GVK EMRI is a pioneer in emergency management services in India. Operating in PPP (public private partnership) mode, GVK EMRI is the largest professional emergency service provider in India. A list of 108-Ambulance and EMTs was obtained. A total of 150 108-ambulances was conveniently selected with their EMTs. The interview was conducted at the base location of ambulances.

\subsection{Study tool}

\subsubsection{Quality of ambulance}

For inspecting the quality of ambulance inspection, parameters set by National Ambulance Services was used which consisted of ten questions on general cleanliness, body maintenance, functioning of medical equipment's, hygienic storage of medical \& other consumables, vehicle maintenance record, functioning of air condition, uniform of the ambulance staff, availability of stepney, and fire extinguisher. The parameters were observed and scored by the investigator. A score of 0 was assigned if the ambulance was not meeting the standards, 1 if it was meeting the standards and 2 if ambulance exceeded the standards resulting in a total maximum score of 20 . Ambulance with quality score not more than ten were considered to have not met the standards and others were considered to have met the standards.

\subsubsection{Knowledge of EMTs}

Understanding the fact that EMTs play an important role in management of emergency cases while transportation, a dichotomous questionnaire was designed to study their knowledge. An interviewer administered questionnaire with 15 questions on five diverse emergency situations was developed by the experts in the field of emergency medicine and was pre tested. Items in the questionnaire were related to the basic care \& quality to be provided to the cases of cardiac arrest, burns, poisoning, road traffic accidents \& pregnancy. Incorrect responses were scored zero. A score of one was assigned to each correct response resulting in a maximum total knowledge score of 15 . The knowledge scores were further classified as below average if the score is not more than 10 and above average otherwise.

\subsection{Ethical approval}

Regulatory \& Ethical permission for the study was obtained from the authorities \& stakeholders of Ambulance Services. Informed Consent was secured, and the importance of the study was explained verbally to each participant before administering the questionnaire.

\subsection{Data collection \& analysis}

The data on ambulance quality and knowledge of emergency medical technicians was collected by the interviewer. Numerical characteristics were summarized as mean \pm standard deviation. Categorical variables were summarized using frequencies and percentages. Chi-squared test of association was used to investigate the association between the quality of ambulance and knowledge of emergency medical technicians. Adjusted association was performed using logistic regression. A p $<0.05$ was considered to be significant throughout. SPSS (Statistical Package for Social Sciences), Version 25 was used for performing the statistical analysis (Fig. 1).

\section{Results}

A total of 150 ambulances were selected with their emergency medical technicians available in the ambulance. All the EMTs were male and had general nursing \& midwifery as their highest degree. The mean age of the emergency medical technicians in the study was $30.1 \pm 2.9$ years with a mean experience of $6.13 \pm 3.21$ years.

Majority of the ambulances $68 \%(n=102)$ were found to have met the standards. In $20 \%(n=30)$ of the ambulances the general cleanliness was not meeting the standards. Almost half $(n=66)$ of the ambulances were not meeting the standards relating to the body of vehicle. Medical equipment's were not meeting the standards in $29.3 \%$ ( $n=44)$ of the ambulance. Only $28.7 \%(n=43)$ ambulances had exceeded the standards of hygienic storage of medical \& non-medical 


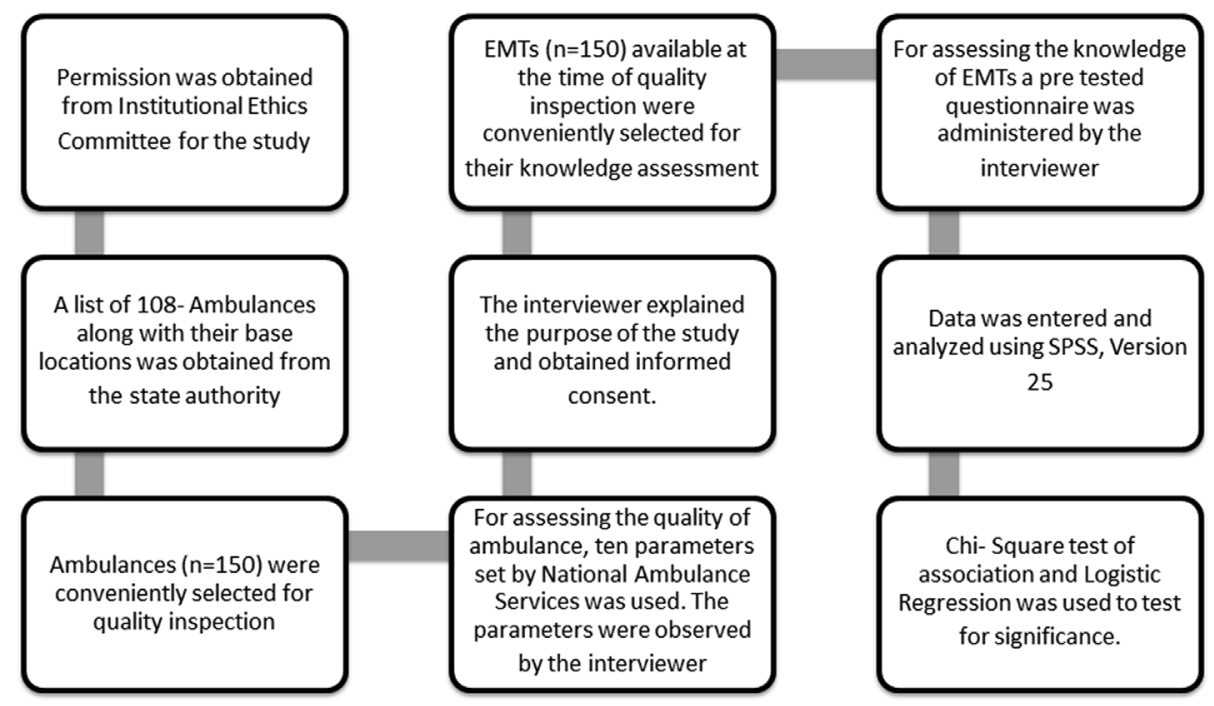

Fig. 1. Flow chart of the study process.

consumable. Majority of the ambulances $92 \%(n=138)$ exceeded the standards of maintaining logbooks, register, PCR (patient care record) and vehicle maintenance record as prescribed.

Air conditioning was not meeting the standards in three-fourth of the ambulances $(n=108)$. Almost half of the EMTs $(n=70)$ were found without uniform i.e., not meeting the standards. One-third of the ambulances $(n=46)$ stepney were not meeting the standards. Fire extinguisher in the ambulance was also not meeting the standards in $48.7 \%(n=73)$ of the ambulance.

Table 1 presents the information regarding quality of ambulance services.

Almost 71\% $(\mathrm{n}=106)$ of the EMTs were observed to have below average knowledge compared to $29 \%(\mathrm{n}=44)$ with above average overall knowledge. Assessment of knowledge during transport of cardiac cases revealed that majority of the participants $(n=142,>90 \%)$ knew to assess vitals. However, $22.7 \%(n=34)$ of the respondents lacked knowledge about the correct ratio of CPR (Cardio-Pulmonary Resuscitation) to be given. Almost $60 \%(\mathrm{n}=92)$ knew the procedure to insert intravenous line for administering drugs.

On being asked about fluid resuscitation $33.3 \%(n=50)$ responded that it is not necessary. Almost $40 \%(n=61)$ of the EMTs responded that it is not essential to cover the burned patient with blanket.

Three fourth of the participants $(n=113)$ responded that delay in EMS (emergency medical services) is a major cause of death in RTA (Road Traffic Accidents). Airway, Breathing \& Circulation was examined by $87.3 \%(n=131)$ of respondents. Majority of the participants $(n=110)$ responded that it is not necessary to avoid feeding in case of RTA.

Majority of the EMTs $(n=124)$ responded that activated charcoal is used for poisoning. Most of the EMTs $(n=123)$ responded that it is necessary to make the patient vomit in case of poisoning management. Almost $40 \%(n=59)$ of the respondents lacked knowledge about symptoms of poisoning.

Assessment of knowledge during transport of pregnant cases revealed that $86.7 \%(n=130)$ respondents were able to conduct deliveries in emergency situations. Also, $92.0 \%(n=138)$ EMTs were able to manage vitals during HRP (high risk pregnancy). Sterility in handling delivery kits was not maintained by $27.3 \%(n=41)$ of participants.

Knowledge questions from each domain and the responses by EMTs are summarized in Table 2.

Among ambulances not meeting the standards, $66.7 \%(\mathrm{n}=32)$ had EMTs with below average knowledge. Of all ambulances meeting the standards, majority 72.5\% $(\mathrm{n}=74)$ had EMTs with below average knowledge. A no significant association between quality of ambulance and knowledge of emergency medical technician $\left(\chi^{2}=0.55, \mathrm{df}=1\right.$, $\mathrm{p}=0.564$ ) was observed. Years of experience and the age of EMTs were inspected for their effect on the relationship between the ambulance quality and the knowledge of EMTs as presented in Table 3. Ambulance quality was found to be independent of the knowledge of EMTs after adjusting for the effects of years of experience and age of the EMTs.

Table 3 Association of ambulance quality and knowledge of EMTs after adjusting for years of experience and age of EMTs.

\section{Discussions}

The presented study revealed essential aspects to help improve the

Table 1

Ambulance quality inspection parameters described $(n=150)$.

\begin{tabular}{|c|c|c|c|}
\hline \multirow{2}{*}{ Ambulance Inspection Parameters } & Does not meet standards & Meets Standards & Exceeds Standards \\
\hline & $\mathrm{n}(\%)$ & n $(\%)$ & n (\%) \\
\hline General Cleanliness of the Ambulance & $30(20)$ & $80(53.3)$ & $40(26.7)$ \\
\hline Ambulance Body Maintenance & $02(1.3)$ & $82(54.7)$ & $66(44)$ \\
\hline Functioning of Medical Equipment's & $44(29.3)$ & $56(37.3)$ & $50(33.4)$ \\
\hline Hygienic Storage of Medical/Non-Medical Consumables & $48(32)$ & $59(39.3)$ & $43(28.7)$ \\
\hline Maintenance of log book, register \& patient care record & $10(6.7)$ & $02(1.3)$ & $138(92)$ \\
\hline Vehicle maintenance record & $12(8)$ & $10(6.7)$ & $128(85.3)$ \\
\hline Functioning of air conditioner & $108(72)$ & $20(13.3)$ & $22(14.7)$ \\
\hline Uniform of ambulance staff & $70(46.7)$ & $0(0)$ & $80(53.3)$ \\
\hline Availability of stepney & $46(30.7)$ & $27(18)$ & $77(51.3)$ \\
\hline Availability of fire extinguisher & $73(48.7)$ & $6(4)$ & $71(47.3)$ \\
\hline
\end{tabular}


Table 2

Knowledge of EMTs necessary during Cardiac Emergencies, Burns Cases, Road Traffic Accident Cases, Poisonous Cases \& Pregnancy Cases $(n=150)$.

\begin{tabular}{|c|c|c|}
\hline \multirow[t]{2}{*}{ Cardiac Emergencies } & \multirow{2}{*}{$\frac{\text { Yes }}{\mathrm{n}(\%)}$} & \multirow{2}{*}{$\begin{array}{l}\text { No } \\
\text { n (\%) }\end{array}$} \\
\hline & & \\
\hline Assessment of Vitals & $142(94.7)$ & $08(5.3)$ \\
\hline $\begin{array}{l}\text { Ability to perform cardiopulmonary resuscitation } \\
\text { (CPR) }\end{array}$ & $116(77.3)$ & $34(22.7)$ \\
\hline $\begin{array}{l}\text { Ability to insert intravenous line for administering } \\
\text { drugs }\end{array}$ & $92(61.3)$ & $58(38.7)$ \\
\hline \multicolumn{3}{|l|}{ Burns Cases } \\
\hline Is airway management necessary? & $132(88)$ & $18(12)$ \\
\hline Is fluid resuscitation important? & $100(66.7)$ & $50(33.3)$ \\
\hline Is it necessary to cover the patient with blanket? & 89 (59.3) & $61(40.7)$ \\
\hline \multicolumn{3}{|l|}{ Road Traffic Accident } \\
\hline Is delay in EMS a major cause of death in RTA? & $113(75.3)$ & $37(24.7)$ \\
\hline Do you check for airway, breathing \& circulation? & $131(87.3)$ & $19(12.7)$ \\
\hline Is it necessary to avoid feeding in case of RTA? & $40(26.7)$ & $110(73.3)$ \\
\hline \multicolumn{3}{|l|}{ Poisoning Cases } \\
\hline Is activated charcoal used for poisoning? & $124(82.7)$ & $26(17.3)$ \\
\hline $\begin{array}{l}\text { Is it necessary to make the patient vomit in case of } \\
\text { poisoning? }\end{array}$ & $123(82.0)$ & $27(18.0)$ \\
\hline Do you know the symptoms of poisoning? & $91(60.7)$ & $59(39.3)$ \\
\hline \multicolumn{3}{|l|}{ Pregnant Cases } \\
\hline Ability to conduct deliveries in emergency situations & $130(86.7)$ & $20(13.3)$ \\
\hline Ability to manage vitals during High Risk Pregnancy & $138(92.0)$ & $12(8.0)$ \\
\hline Sterility maintained in handling Pregnancy Kit & $109(72.7)$ & $41(27.3)$ \\
\hline
\end{tabular}

Table 3

Association of ambulance quality and knowledge of EMT after adjusting for years of experience and age of EMT.

\begin{tabular}{lll}
\hline Characteristics & Unadjusted OR (95\% CI) & Adjusted OR (95\% CI) \\
\hline Knowledge $^{\mathrm{a}}$ & $1.32(0.63,2.77)$ & $1.97(0.87,4.47)$ \\
Years of Experience & $0.83(0.74,0.92)$ & $0.67(0.54,0.82)$ \\
Age & $0.92(0.82,1.03)$ & $1.30(1.05,1.61)$ \\
\hline
\end{tabular}

a Ref category: above average knowledge; OR: Odds Ratio.

quality of ambulances. Being one of the most important components of the quality, general cleanliness needs to be addressed on priority. Compartment area of the patient in the ambulances if not cleaned and disinfected properly may lead to infections which might worsen the condition of on-board patient. Similar findings were revealed in the study from Saudi Arabia ${ }^{20}$ which concluded that there is almost $80 \%$ growth of harmful bacteria if the patient compartment of the ambulance is not fumigated. The presented study revealed that majority of ambulances did not meet the standards with respect to the body of the vehicle. Studies ${ }^{21}$ reveal the importance of having a proactive maintenance plan in preventing emergency run breakdowns, prolong the life of vehicle, avoid costly repairs and reduce costly vehicle downtime. Medical equipment's play a vital role in diagnosis and saving life of patients in the pre-hospital care setting, i.e. ambulances. Fitted with various equipment's and gadgets, modern ambulances are marvel of technology. ${ }^{22}$ In the presented study the medical equipment's in the ambulance were not meeting the standards. A study ${ }^{23}$ from healthcare workers evidenced similar findings that medical \& non-medical consumables in the ambulances if not stored in a proper manner leads to various infections. It also tells that proper education of EMS providers on the importance of safety at a microscopic level can drastically reduce the chances of infections associated with healthcare. ${ }^{24}$ As per retention and disposal of records policy \& procedure for medical records, all records in the ambulance should be managed in a way that allows the information contained within the ambulance to be available whenever demanded by the higher authorities for audit purpose. ${ }^{25}$ In the presented study these criteria's were exceeding the standards.

The presented study revealed that the air conditions in the ambulance were not meeting the standards. Previous studies ${ }^{26}$ revealed that proper air cooling is important in the ambulance for storing medications in a suitable temperature. It is also important in various emergency situations like burn cases, hypotensive patients, etc. where airconditioning plays a vital role in saving patient's life. Researches shave shown that uniform of any healthcare professional confers a power on their status ${ }^{27}$ but in this study it was lacked by the EMTs. Stepney in the ambulances can maintain the concept of golden hour when the running tire gets damaged or puncture ${ }^{28}$ by quickly changing it. Our findings revealed stepney was not meeting the standards. It is also evidenced from our study that fire extinguisher was not meeting the standards while studies ${ }^{29}$ have suggested that it is important to have fire extinguisher in the ambulance to prevent worsening of the situation in case of a fire emergency.

Proper and effective CPR proves to be lifesaving till the patient is handed over in the healthcare facility as evidenced from previous studies. ${ }^{30}$ In this study participants lacked proper knowledge on correct ratio of CPR. A study ${ }^{31}$ concluded that it is absolutely necessary to cover the patient with blanket since it minimizes the amount of oxygen which prevents the severity of burn but in our study the participants didn't find it necessary to do the same. They also responded that the delay in EMS is because of poor conditions of road construction, poor connectivity to remote areas and worsening traffic conditions. A study conducted in southern India suggests avoiding feeding in case of RTA to avoid patient choking. ${ }^{32}$ The present findings were dissimilar from the study of southern India. It is evidenced and proved by an article ${ }^{33}$ that without understanding the signs and symptoms proper \& effective management cannot be established. Presented study revealed that EMTs lacked symptoms of poisoning. Using sterile \& aseptic technique helps in preventing many harmful pathogenic infections. ${ }^{34}$ But in this study, the participants didn't maintained sterility.

This study adds to our existing knowledge on the ambulance quality and the knowledge of EMTs however there are few limitations of the presented work. The 95\% CI of odds ratio on knowledge of EMTs as reported in Table 3 is indicative of a probable need to increase the sample size. Future research with larger sample size should be taken up in this field to help establish the relationship with greater precision.

\section{Conclusions}

Majority of the ambulances maintained above average quality however most of the EMTs were found to have below average knowledge of care to be provided during transportation. Timely inspection of the ambulances by quality assurance cell of health department is important. Installing disinfection system in ambulances to protect patients and healthcare providers from infections is highly recommended. The existing ambulances should be well equipped with state of art facilities to increase the efficiency and effectiveness instead of increasing the number of ambulances. This exploratory study serves as an eye-opener to health officials and public health workers.

\section{Source of funding}

Nil.

\section{Authors contributions}

Bhaskar Tiwary \& Piyusha Majumdar were responsible for study conception, design \& data collection. Monika Singh \& Mohd. Aihatram Khan formed the manuscript. Nilima Nilima provided statistical expertise, critically revised the manuscript and formed final draft along with Bhaskar Tiwary.

\section{Declaration of competing interest}

The authors claim no conflict of interest. 


\section{Acknowledgement}

Authors thank the research investigators \& ambulance paramedics for their support \& cooperation. Authors would also like to acknowledge Mr. Rahul Singh (B. Tech, Mechanical Engineering) for proofreading this article.

\section{References}

1. Das S, Desai R. Emergence of EMS in India. 2017; 2017 (Sat).

2. Pasha I. Ambulance management system using GIS. Universitetsbibliotek. 2006.

3. Majdan M, Plancikova D, Maas A, et al. Years of life lost due to traumatic brain injury in Europe: a cross-sectional analysis of 16 countries. PLoS Med. 2017;14(7):e1002331.

4. Gomes M, Begum R, Sati P, et al. Nationwide mortality studies to quantify causes of death: relevant lessons from India's Million Death Study. Health Aff. 2017;36(11):1887-1895.

5. Channa R, Jaffrani HA, Khan AJ, Hasan T, Razzak JA. Transport time to trauma facilities in Karachi: an exploratory study. Int J Emerg Med. 2008;1(3):201.

6. Sharma M, Brandler ES. Emergency medical services in India: the present and future. Prehospital Disaster Med. 2014;29(3):307-310.

7. Babiarz KS, Mahadevan SV, Divi N, Miller G. Ambulance service associated with reduced probabilities of neonatal and infant mortality in two Indian states. Health Aff. 2016;35(10):1774-1782.

8. Razzak JA, Kellermann AL. Emergency medical care in developing countries: is it worthwhile? Bull World Health Organ. 2002;80:900-905.

9. Joshipura MK, Shah HS, Patel PR, Divatia PA, Desai PM. Trauma care systems in India. Injury, 2003;34(9):686-692.

10. Hohlagschwandtner M, Husslein P, Klebermass K, Weninger M, Nardi A, Langer M. Perinatal mortality and morbidity. Arch Gynecol Obstet. 2001;265(3):113-118.

11. Sharma M, Brandler ES. Emergency medical services in India: the present and future. Prehospital Disaster Med. 2014;29(3):307-310.

12. John AE, Nilima Nilima, Binu VS, Unnikrishnan B. Determinants of antenatal care utilization in India: a spatial evaluation of evidence for public health reforms. Public Health. 2019 Jan 1;166:57-64.

13. Nilima Nilima, Kamath A, Shetty K, Unnikrishnan B, Kaushik S, Rai SN. Prevalence, patterns, and predictors of diarrhea: a spatial-temporal comprehensive evaluation in India. BMC Publ Health. 2018 Dec 1;18(1):1288.

14. Singh SK. Road traffic accidents in India: issues and challenges. Transport. Res. Procedia. 2017;25:4708-4719.

15. Mohammadi M, Amir AN, Fakhri M, et al. The evaluation of time performance in the emergency response center to provide pre-hospital emergency services in Kermanshah. Global J Health Sci. 2015;7(1):274

16. Morey RC, Fine DJ, Loree SW, Retzlaff-Roberts DL, Tsubakitani S. The trade-off between hospital cost and quality of care: an exploratory empirical analysis. Med Care. 1992:677-698.
17. Mehmood A, Rowther AA, Kobusingye O, Hyder AA. Assessment of pre-hospital emergency medical services in low-income settings using a health systems approach. Int J Emerg Med. 2018;11(1):53.

18. Mohanan M, Hay K, Mor N. Quality of health care in India: challenges, priorities, and the road ahead. Health Aff. 2016;35(10):1753-1758.

19. Garg RH. Who killed Rambhor?: the state of emergency medical services in India. $J$ Emergencies, Trauma, Shock. 2012;5(1):49.

20. Alrazeeni D, Al Sufi MS. Nosocomial infections in ambulances and effectiveness of ambulance fumigation techniques in Saudi Arabia: phase I study. Saudi Med J. 2014;35(11):1354

21. Levick NR. New safety initiatives in ambulance transport-measuring and managing hazards, risk and crashworthiness outcomess in the EMS environment. Annual Proceedings/Association for the Advancement of Automotive Medicine. 2003; 2003:620 (Association for the Advancement of Automotive Medicine).

22. Siddiqi S, Kielmann AA, Khan MS, et al. The effectiveness of patient referral in Pakistan. Health Pol Plann. 2001;16(2):193-198.

23. Muntlin $\AA$, Gunningberg L, Carlsson M. Patients' perceptions of quality of care at an emergency department and identification of areas for quality improvement. J Clin Nurs. 2006;15(8):1045-1056.

24. Wong SS, Huang CH, Yang CC, et al. Reducing health care-associated infections by implementing separated environmental cleaning management measures by using disposable wipes of four colors. Antimicrob Resist Infect Contr. 2018;7(1):34.

25. Putul M, Mukesh Y. Documentation of medical record in day-to-day medical practice IJHRMLP. 2016;2:29 01 .

26. Crichton B. Keep in a cool place: exposure of medicines to high temperatures in general practice during a British heatwave. J R Soc Med. 2004;97(7):328-329.

27. Shaw K, Timmons S, PGCAP B. Exploring how nursing uniforms influence self image and professional identity. Nurs Times. 2010;106(10):21-23.

28. Buyske J. Emergency Medical Services and Public Policy in Durban. 2016; 2016 (Kwazulu-Natal).

29. Williams M, Braddock M. AI case studies: potential for human health, space exploration and colonisation and a proposed superimposition of the kubler-ross change curve on the hype cycle. Stud Humana. 2019;8(1):3-18.

30. Okonta KE, Okoh BA. Theoretical knowledge of cardiopulmonary resuscitation among clinical medical students in the University of Port Harcourt, Nigeria. African $J$ Med Health Sci. 2015;14(1):42.

31. Hinshaw JL, Lubner MG, Ziemlewicz TJ, Lee Jr FT, Brace CL. Percutaneous tumor ablation tools: microwave, radiofrequency, or cryoablation-what should you use and why. Radiographics. 2014;34(5):1344-1362.

32. Joseph N, Kumar GS, Babu YR, Nelliyanil M, Bhaskaran U. Knowledge of first aid skills among students of a medical college in Mangalore city of South India. Ann Med Health Sci Res. 2014;4(2):162-166.

33. Kumar S, Agarwal AK, Kumar A, Agrawal GG, Chaudhary S, Dwivedi V. A study of knowledge, attitude and practice of hospital consultants, resident doctors and private practitioners with regard to pre-hospital and emergency care in Lucknow. Indian $J$ Surg. 2008;70(1):14-18.

34. Hart D. Bactericidal ultraviolet radiation in the operating room: twenty-nine-year study for control of infections. J Am Med Assoc. 1960;172(10):1019-1028. 